\title{
Quatro horas de Química
}

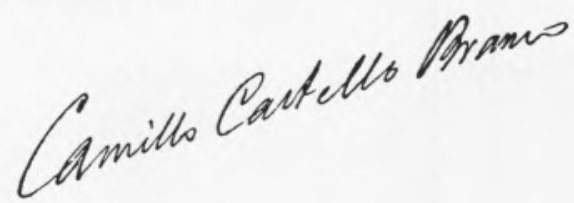

"Estudava eu Química na Academia do Porto $^{1}$. De dois condiscípulos somente me recordo bem. Um era o melhor estudante; o outro, seria o pior do curso, se eu lá não estivesse.

$\mathrm{O}$ primeiro era Farmacêutico: chamava-se Amorim e Vasconcelos (...). O nosso lente, o

\section{ÉLÉMENTS \\ DE CHIMIE,}

M. ORFIA,

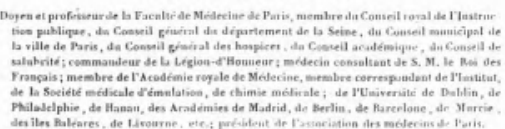

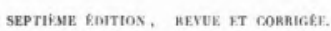

TOME PREMIEH.

PARIS,

FORTIN, MASSON ET C", LIBRAIRES MLAce be t'kcatk-pt-Mknecass, I.

1843

Frontispício da $7^{\mathrm{a}}$. edição dos "Éléments de Chimie" de Orfila, publicada no ano em que Camilo se matricula em Química. O compêndio por onde o romancista deveria ter estudado "era o Lassaigne, que alguns condiscipulos generosos me emprestavam à porta da Academia, quando se avistava 0 lente, um ex-frade, Santa Clara, contemporâneo de Orfila, Berzelius e Liebig. Por que mãos sagradas andava então a quimica portuguesa!" (in "O General Carlos Ribeiro").

senhor Frei Joaquim de Santa Clara de Sousa Pinto, nunca teve o gosto de nos ouvir. (...) Fugíamos às recuadas, quando o nosso condiscípulo farmacêutico tinha absorvidas as atenções com a sua eloquência recamada de protos, de deutos, de bis, de sesqui, de pilhas, de retortas, e várias coisas com que os homens entretêm a vida para não morrerem de tédio.

(......)

$\mathrm{O}$ meu ponto era o Kermes mineral ${ }^{2}$ e não sei que mais. (...) Ao anoitecer, ainda eu não sabia a que página do livro estava a matéria do ponto. Deliberei às nove horas da noite não fazer acto, e fui ouvir a música à porta do quartel-general.

Estava eu embevecido na ária da Norma, quando senti no ombro pousar-se-me amigável mão.

- O senhor por aqui?! perguntou-me alguém.

Voltei-me e vi o meu sábio condiscípulo Amorim e Vasconcelos, o estudante premiado, que, naquele tempo, devia orçar pelos seus trinta anos, e já era administrador da botica do Hospital da Trindade, se bem me lembro.

- Por aqui em vésperas de ponto?! tornou ele.

- É verdade...

- Já estudou?

- Nada.

- Então?!

- Não vou fazer acto.

- Porque não sabe o ponto?

- Justamente.

- Venha comigo, que eu ensino-lho. Venha, que é uma desgraça perder um ano!

E levou-me pelo braço.

Escutei-o até às duas da madrugada.

Quando saí, sabia o ponto, sabia os rudimentos da Química, sabia a história e a filo- 


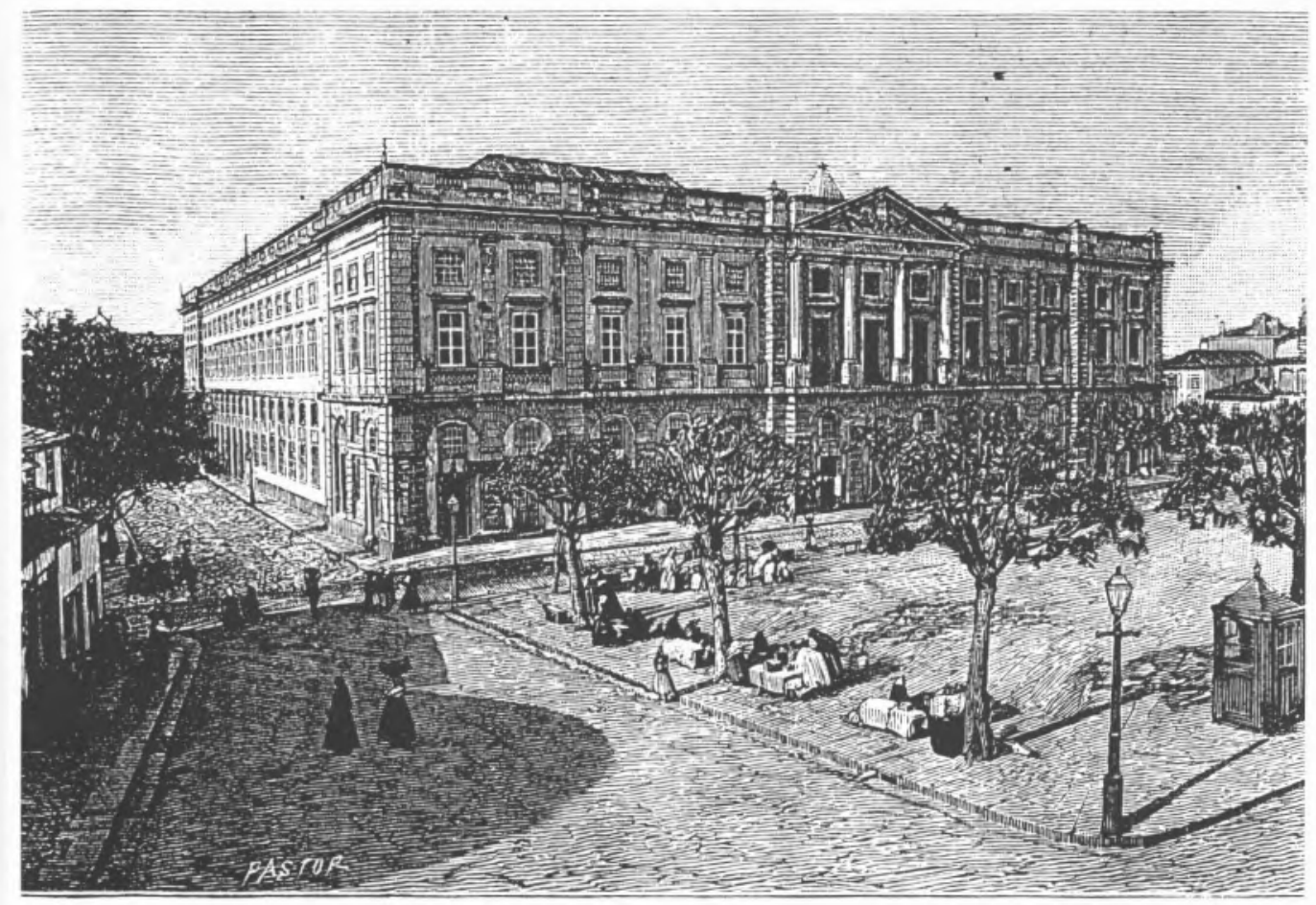

Acidema Polytechnica do Ponto

(Segundo uma photographia moderna)

Academia Politécnica do Porto. Fundada em 1837, em simultâneo com a Escola Politécnica de Lisboa. Foi neste edifício que entre 1883 e 1907 funcionou o Laboratório Municipal de Química, dirigido por Ferreira da Silva. Pertence actualmente à Faculdade de Ciências da Universidade do Porto.

sofia das ciências, conhecia Berzelius, GayLussac, Orfila ${ }^{3}$ e não sei quem mais.

\section{(......)}

Soou a hora do acto. Já de antemão os condiscípulos me davam pêsames. (...) O senhor de Santa Clara estava na presidência com ar fúnebre. (...) Eu ia alegre com a minha ciência e três cálices de licor de canela.

Que acto eu fiz! Desenruguei a fronte do lente, enchi de júbilo os arguentes, espantei os condiscípulos e fui aprovado nemine discrepante $^{4}$. (...) Amorim abraçara-me (...).

Radiava de alegria o bom homem. (...) Criara-me a reputação em quatro horas, com a sua linguagem tersa, clara, insinuante e amena como devera ser o método de quem ensinasse química a senhoras. (...). Amorim era doutíssimo na sua especialidade, e, sem favor, o primeiro químico experimental do
Porto. (.....). Devo à sua memória esta notícia em paga de me ele ajudar a fingir uma vez que eu sabia química."

"O meu condiscípulo", in "Cavar em Ruínas", 1867.

${ }^{1} \mathrm{Em} 1843-44$, entre os 18 e os 19 anos.

${ }^{2}$ Ou quermes mineral, oxissulfureto de antimónio, $\mathrm{Sb}_{2} \mathrm{~S}_{2} \mathrm{O}$, usado à época como medicamento expectorante, de cor vermelha semelhante à do corante quermes, obtido de insectos com o mesmo nome.

${ }^{3}$ M. Orfila (1787-1853). Químico espanhol. Deão da Faculdade de Medicina de Paris. É considerado o fundador da toxicologia moderna. Autor de uns " Éléments de Chimie " que tiveram sucessivas ediçōes.

${ }^{4}$ Por unanimidade. 

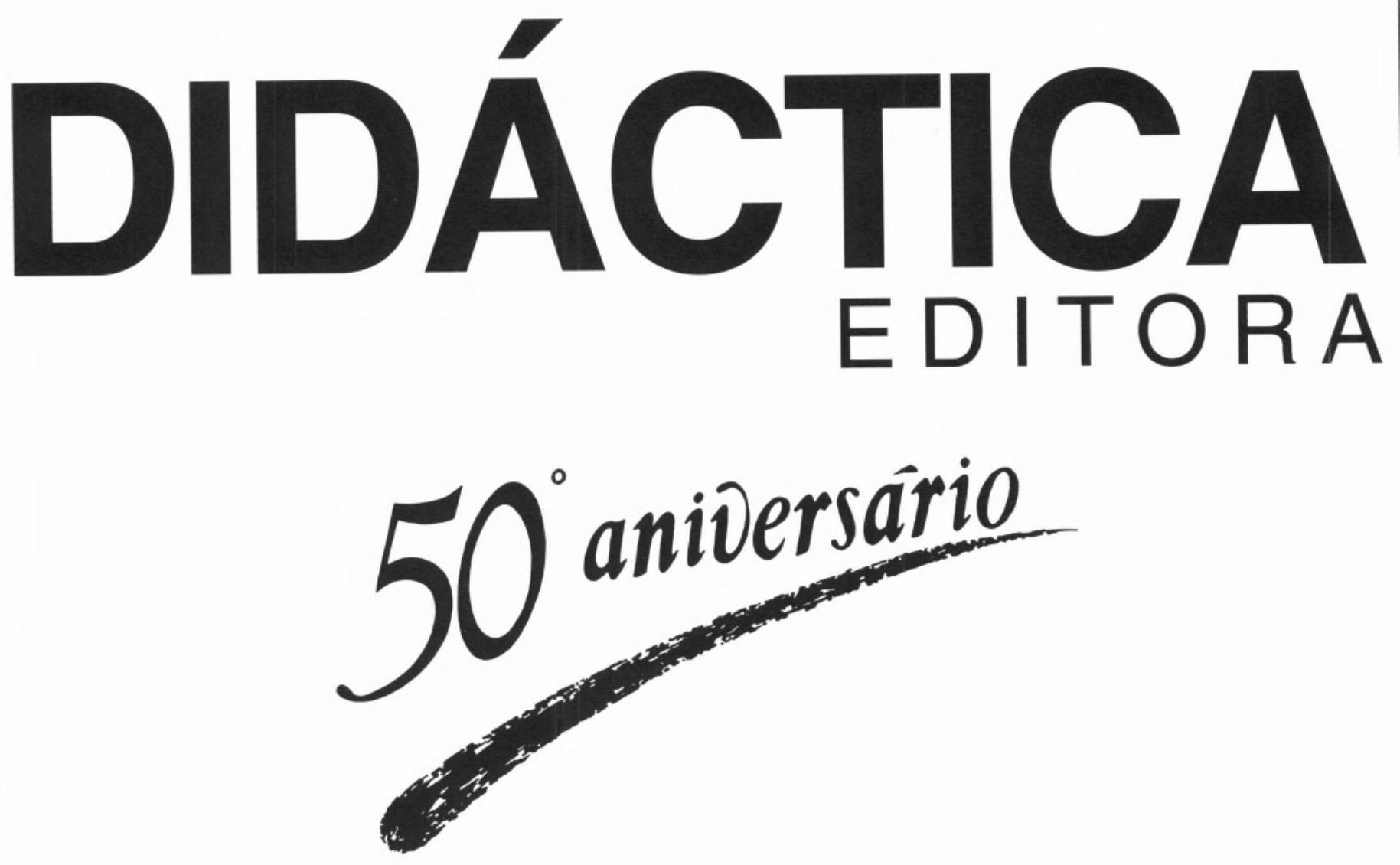

\section{QUÍMICA 8. ${ }^{\circ}$ Ano}

L U Í S S I L V A JORGE VALADARES VÍTOR TEODORO CARLOS FIOLHAIS

QUÍMICA 10. Ano

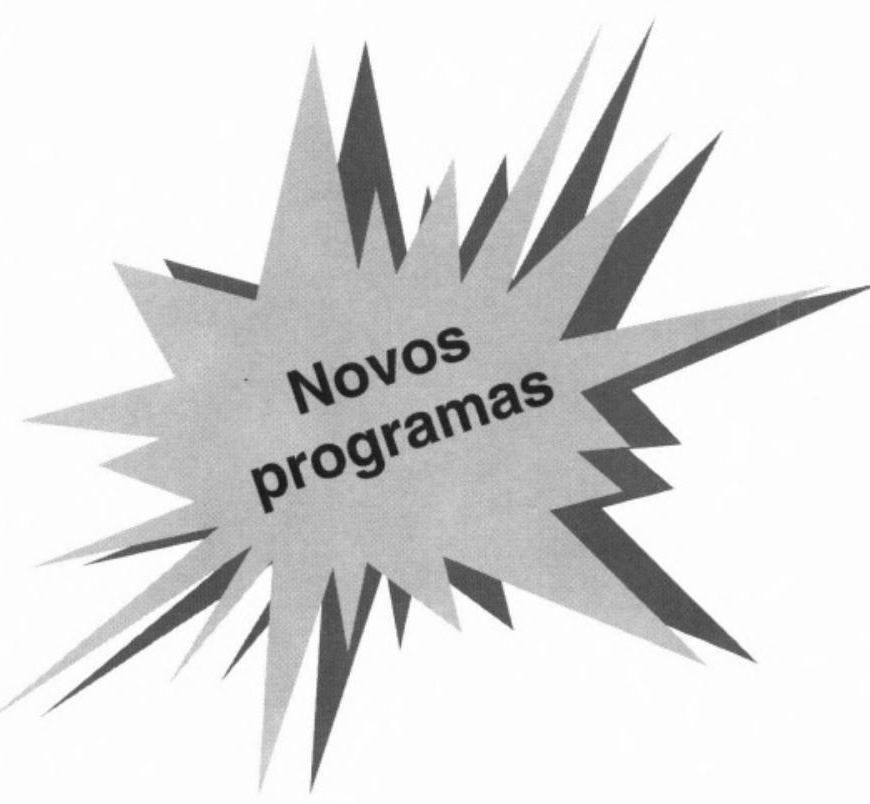

VÍTOR TEODORO

ANTÓNIO MANUEL

NUNES DOS SANTOS 